\title{
PHARMACOKINETIC PROFILE OF 75 MG CLOPIDOGREL IN PLASMA OF INDONESIAN HEALTHY SUBJECTS BY ULTRA HIGH-PERFORMANCE LIQUID CHROMATOGRAPHY-TANDEM MASS SPECTROMETRY
}

\author{
YAHDIANA HARAHAP*, GANESYA RITA PUTRI, HERMAN SURYADI
} Department of Bioavailability/Bioequivalence Laboratory, Faculty of Pharmacy, Universitas Indonesia, Depok, 16424, Indonesia.
Email: yahdiana03@yahoo.com

Received: 08 June 2018, Revised and Accepted: 09 August 2018

\section{ABSTRACT}

Objective: This study aimed to determine clopidogrel in plasma to obtain its pharmacokinetic profile using ultra-high-performance liquid chromatography-tandem mass spectrometry (UPLC-MS/MS).

Methods: Clopidogrel analysis was performed in vivo by UPLC-MS/MS using validated methods. Subjects received 75 mg clopidogrel, and plasma samples were collected at 14 time points after 0 baseline (pre-dose): $0.25,0.5,0.75,1,1.25,1.5,2,3,4,8,12,18$, and $24 \mathrm{~h}$.

Results: A linear calibration curve was produced in the range of $20-5.000 \mathrm{pg} / \mathrm{mL}$. This method fulfills the criteria for validation according to the European Medicines Agency guidelines. The obtained pharmacokinetic profile of clopidogrel was as follows: Maximum concentration=1.146 ng/mL, time at maximum concentration $\left(\mathrm{t}_{\max }\right)=1 \mathrm{~h}$, half-life $\left(\mathrm{t}^{1} \frac{1}{2}\right)=7.01 \mathrm{~h}$, area under curve (AUC) $)_{0-\mathrm{t}}=7.420 \mathrm{ng} \mathrm{h} / \mathrm{mL}$, and AUC ${ }_{0-\mathrm{t}}=8.111 \mathrm{ng} \mathrm{h} / \mathrm{mL}$.

Conclusion: Clopidogrel analysis using a UPLC/MS-MS system with liquid-liquid extraction method was successfully conducted using plasma samples from three healthy subjects who administered $75 \mathrm{mg}$ of clopidogrel tablet.

Keywords: Clopidogrel, Ultra-high-performance liquid chromatography-tandem mass spectrometry, Plasma, Pharmacokinetic profile, Bioanalysis.

(c) 2018 The Authors. Published by Innovare Academic Sciences Pvt Ltd. This is an open access article under the CC BY license (http://creativecommons. org/licenses/by/4. 0/) DOI: http://dx.doi.org/10.22159/ijap.2018.v10s1.73

\section{INTRODUCTION}

Clopidogrel is a cardiovascular drug that functions as a platelet aggregation inhibitor. It prevents the formation of blood clots through adenosine diphosphate blockage by binding with P2Y12 receptors on the surface, causing GPIIb/IIIa glycoprotein complex inactivation such that platelets do not clot. Clopidogrel belongs to the thienopyridine group of chemicals and is metabolized by the CYP450 enzyme in the liver, which produces active and inactive metabolites. The active metabolites bind with platelet receptors in a fast and irreversible way [1].

As a cardiovascular drug indicated for serious conditions, clopidogrel requires a bioequivalence test [2]. Clopidogrel metabolites can convert back into clopidogrel. The responsible clopidogrel form that causes reconversion is clopidogrel acyl glucuronide, which is altered from carboxylic clopidogrel by the UDP-glucuronyltransferase enzyme. The level of clopidogrel acyl glucuronide in the blood can reach 500 times higher than the level of clopidogrel; thus, clopidogrel levels measured in plasma often do not reflect actual levels [3-6].

Drug bioequivalence testing should use a validated bioanalysis method. A selective and sensitive measurement technique is required to measure the smallest level of drug still present in the blood [7]. The maximum concentrations $\left(\mathrm{C}_{\max }\right)$ of clopidogrel reported in previous research were $2.10 \mathrm{ng} / \mathrm{mL}, 1.70 \mathrm{ng} / \mathrm{mL}$, and $1.86 \mathrm{ng} / \mathrm{mL}$ [5-7]. Based on previous research, the LLOQ value should be obtained at $85 \mathrm{pg} / \mathrm{mL}$, that is, $5 \%$ of clopidogrel $\mathrm{C}_{\text {max }}$. In this research, the analytical method was developed for determining clopidogrel in plasma to obtain its pharmacokinetic profile using LC-tandem mass spectrometry (MS)/MS.

\section{MATERIALS AND METHODS}

Study design

As a pilot study, three healthy subjects were given one clopidogrel tablet at a dose of $75 \mathrm{mg}$ after fasting. The subjects met the exclusion and inclusion criteria. According to the Food and Drug Administration, pilot studies can be done with a small number of subjects before full bioequivalence studies [8,9]. Blood samples were collected at 14 time points, namely 0 (pre-dose), $0.25,0.5,0.75,1,1.25,1.5,2,3,4,8,12,18$, and $24 \mathrm{~h}$, and then analyzed using validated bioanalytical methods. The sampling time should be 3 or more times the half-life. The half-life of clopidogrel was reported as $6.9 \mathrm{~h}$ in a previous study [10].

Before blood samples were taken, each subject was given an explanation of the research and provided informed consent. This study was approved by the Medical Research Ethics Committee of Medical Faculty, Universitas Indonesia (No.306/UN2.F1/ETIK/III/2017).

\section{Tools}

This study used a set of ultra-high-performance liquid chromatography (UPLC)-MS/MS (Waters Xevo TQD Triple Quadrupole) including a Quaternary Solvent Manager (Acquity UPLC H-Class), Sample Manager (Acquity UPLC), nitrogen generator compressor (PEAK Scientific), BEH C18 Column (Waters Acquity ${ }^{\mathrm{TM}}$ UPLC $1.7 \mu \mathrm{m}, 2.1 \mathrm{~mm} \times 100 \mathrm{~mm}$ ), mass analyzer of triple quadrupole (Xevo TQD) with an ionization source (Zspray ${ }^{\mathrm{T}}$ ), Data Processing Software (MassLynx Software), a computer (Lenovo), microcentrifuge tubes, autosampler vials, $0.2 \mu \mathrm{m}$ Millipore membrane, analytical balance, ultrasonic stirrer (Elmasonic), refrigerator, freezer, gas remover (Elmasonic S40H), vortex (Maxi Mix II), and glassware.

\section{Materials}

The blank plasma from Indonesian Red Cross and plasma samples isolated from the blood of three healthy subjects given a $75 \mathrm{mg}$ clopidogrel tablet (single dose). Additional materials included standard clopidogrel (MSN Laboratories), irbesartan as an internal standard (Zhejiang Huahai Pharmaceutical), HPLC grade aquabidest (Merck), HPLC grade acetonitrile (Merck), formic acid (Merck), diethyl ether (Merck), ammonium acetate (Merck), and Plavix tablet containing $75 \mathrm{mg}$ clopidogrel. 


\section{Stock solution}

Clopidogrel and irbesartan (internal standard) were weighed to $10.0 \mathrm{mg}$ and dissolved in acetonitrile to a concentration of $0.1 \mathrm{mg} / \mathrm{mL}$. Dilution was performed to achieve certain concentrations.

\section{System suitability test}

As much as $5 \mathrm{l}$ of the mixture of clopidogrel and irbesartan solution at a concentration of $100 \mathrm{ng} / \mathrm{mL}$ was injected into the UPLC-MS/MS system, and evaluate the $\mathrm{CV}$ of retention times and area of analytes and internal standards.. The repeated value coefficient of variation percentage $(\%$ $\mathrm{CV}$ ) results from five injections were recorded and calculated as the ratio of area and retention time of the analyte and internal standard.

\section{Sample preparation}

A volume of $250 \mu \mathrm{L}$ plasma containing the analyte was mixed with as much as $20 \mu \mathrm{L}$ of irbesartan solution at a concentration of $100 \mathrm{ng} / \mathrm{mL}$. The sample was mixed by vortex for $30 \mathrm{~s}$. Extraction was done by the liquid-liquid extraction. The sample was mixed with as much as $250 \mu \mathrm{L}$ of $50 \mathrm{mM}$ ammonium acetate $(\mathrm{pH}$ 6.8) and vortexed for $10 \mathrm{~s}$. Next, $1 \mathrm{~mL}$ of diethyl ether was added and vortexed for 2 min followed by centrifugation at $3000 \mathrm{rpm}$ for $10 \mathrm{~min}$. After the supernatant was separated, $800 \mu \mathrm{L}$ of the organic phase was transferred to another microtube for evaporation at $10 \mathrm{~min}$ at $60^{\circ} \mathrm{C}$. The residue was then reconstituted in $150 \mu \mathrm{L}$ acetonitrile and vortexed for $10 \mathrm{~s}$. Finally, $5 \mu \mathrm{L}$ of the aliquot was injected to UPLC-MS/MS.

\section{Validation of bioanalysis methods [11].} Calibration curves

A total of 8 plasma samples with clopidogrel concentrations of 20,100, $200,1000,2500,4000$, and $5000 \mathrm{pg} / \mathrm{mL}, 20 \mu \mathrm{L}$ of the internal standard $100 \mathrm{ng} / \mathrm{mL}$, blank samples (plasma without internal standard), and zero samples (plasma with internal standard) were prepared. A total of $10 \mu \mathrm{L}$ of the final solution for each concentration was injected into the UPLC-MS/MS system. The peak area obtained was recorded, and then the calibration curve was made. Linearity was determined by the linear regression equation and calculation of the correlation coefficient (r). The calculation of percentage difference with the limit values of percentage difference was $< \pm 15 \%$ for all concentrations, except LLOQ not $>20 \%$.

\section{Within-run accuracy and precision}

Aliquots from a plasma blank were prepared and mixed with $\mathrm{QC}$ solutions at low (QCL), medium (QCM), and high (QCH) concentrations with the addition of $20 \mu \mathrm{l}$ of the $100 \mathrm{ng} / \mathrm{mL}$ internal standard. Samples were prepared, and $10 \mu \mathrm{L}$ of the final solution was injected into the UPLC-MS/MS system. The test was performed with five replicas. The percentage difference and percentage $\mathrm{CV}$ values were calculated to determine accuracy and precision, respectively. The percentage difference and percentage CV values did not exceed $15 \pm \%$ for all concentrations except LLOQ, which did not exceed $\pm 20 \%$.

\section{Preparation and collection of healthy subject blood samples}

Blood samples were collected before and after healthy subjects administered $75 \mathrm{mg}$ clopidogrel tablet. Post-dose samples were collected at $0.25,0.5,0.75,1,1.25,1.5,2,3,4,8,12,18$, and $24 \mathrm{~h}$. Samples were taken by a phlebotomist using the venipuncture technique and a syringe. Samples were collected in $9 \mathrm{~mL}$ in vacuum tubes containing heparin anticoagulant. Plasma was isolated from the blood and then prepared and analyzed using UPLC-MS/MS

\section{Pharmacokinetics calculations}

The obtained data were used to calculate clopidogrel levels. The pharmacokinetics calculations were performed using the following parameters: $\mathrm{C}_{\max }$, time at maximum concentration $\left(\mathrm{t}_{\max }\right), \mathrm{t}^{\mathrm{t}} / 2$ (half-life), area under curve (AUC) $)_{0-\mathrm{r}^{-}}$and $\mathrm{AUC}_{0-\infty}$

\section{RESULTS AND DISCUSSION}

\section{System suitability test}

After the optimum conditions were confirmed, a system suitability test was performed to ensure that the analysis provided good and consistent results. The system suitability test was performed on a mixture of $100 \mathrm{ng} / \mathrm{mL}$ clopidogrel and $100 \mathrm{ng} / \mathrm{mL}$ irbesartan. The mixed solution was injected 5 times in $5 \mu$ injection volumes, and then the percentage $\mathrm{CV}$ from the retention time and the peak area of analyte and internal standard were obtained. For clopidogrel, the CV was equal to $0.247 \%$ for area and $0.202 \%$ for retention time. For irbesartan, the CV was equal to $0.784 \%$ for area and $0.462 \%$ for retention time. The results of the system suitability test fulfilled the requirement of $\leq 2 \%$ of percentage CV for area and retention time.

\section{Validation of bioanalysis methods Calibration curves}

The range of the calibration curve for clopidogrel was $20-5000 \mathrm{pg} / \mathrm{mL}$ based on the seven concentrations, namely 20, 100, $200,1000,2500,4000$, and $5000 \mathrm{pg} / \mathrm{mL}$ plus the blank and zero samples. The correlation coefficient was 0.9987 with a linear regression equation $y=0.1585+0.0009 x$. These data show that the obtained calibration curve was linear. The percentage difference value for the clopidogrel calibration curve fulfilled the requirements of $11.86 \%$ at LLOQ concentrations and $-8.57 \%$ to $14.16 \%$ at other concentrations. The LLOQ value of clopidogrel was good because it could measure concentrations up to $20 \mathrm{pg} / \mathrm{mL}$. However, the obtained LLOQ was still higher than that reported by Robinson et al. of $10 \mathrm{pg} / \mathrm{mL}$ [12]. The clopidogrel analysis method used in this study can be applied in in vivo with a LLOQ value of $20 \mathrm{pg} / \mathrm{mL}$ because the LLOQ value requirement is at least $5 \% \mathrm{C}_{\max }$ clopidogrel.

\section{Within-run accuracy and precision}

The within-run accuracy and precision were performed to determine the proximity between the measured concentrations and actual concentrations, as well as the proximity of repeatable analytical measurements, by determining the percentage difference values for accuracy and percentage CV values for precision. The accuracy and precision requirements are $\leq \pm 20 \%$ at LLOQ concentrations and $\leq \pm 15 \%$ at other concentrations. The results of the within-run accuracy for clopidogrel fulfilled the requirements with percentage difference values of $-1.06-13.80 \%$ at LLOQ concentration and $-4.17-14.86 \%$ at other concentrations. The within-run precision for clopidogrel also met the requirements with percentage CV values of $6.60 \%$ at LLOQ, 6.18\% on QCL, $5.01 \%$ on QCM, and $4.65 \%$ on QCH. Although the percentage difference and percentage $\mathrm{CV}$ values obtained were different from previous studies, the accuracy and precision results still met the requirements and showed that the analytical methods used here were accurate and precise.

\section{Sample analysis}

The sample analysis, calibration curve, and QC sample results for each subject are presented in Table 1 . The measured clopidogrel concentrations in plasma are plotted as plasma concentration versus time curves in Figs. 1-3. The $\mathrm{C}_{\max }$ values from subjects 1,2 , and 3 were $1.07,1.11$, and $1.25 \mathrm{ng} / \mathrm{mL}$, respectively, with an average of $1.15 \mathrm{ng} /$ $\mathrm{mL}$. The $\mathrm{t}_{\max }$ value for subjects 1 and 3 was $1 \mathrm{~h}$, whereas the $t_{\max }$ value for 2 was $1.25 \mathrm{~h}$. The $\mathrm{C}_{\text {max }}$ and $\mathrm{t}_{\max }$ values indicated the absorption rate of a drug in the body. The $C_{\max }$ value shows the maximum drug concentration in plasma after drug administration. The $t_{\max }$ value is the time when the drug concentration in plasma reaches its peak, and the absorption of the drug is greatest, and when the drug absorption rate is equal to the drug elimination rate. The low $t$ value indicates that the drug absorption rate is rapid. The average $\mathrm{C}_{\max }$ value of $5 \%$ in this study was about $57.5 \mathrm{pg} / \mathrm{mL}$; this value is greater than the LLOQ value obtained using this method, namely $20 \mathrm{pg} / \mathrm{mL}$. This value meets the EMA requirement that LLOQ should not be $>5 \%$ of the $C_{\text {max }}$ of the analyte in the body $\left(\mathrm{C}_{\text {max }}\right)$. These results suggest that the validated analytical methods were successfully applied in vivo.

$\mathrm{AUC}_{0-\mathrm{t}^{\prime}} \mathrm{AUC}_{0-\infty}$, and $\mathrm{t} 1 / 2$ (half-life) were measured by plotting the data of plasma drug concentration versus time. The $\mathrm{AUC}_{0-\mathrm{t}}$ values for subjects 1,2 , and 3 were $7.87,6.69$, and $7.69 \mathrm{ng} \mathrm{h} / \mathrm{mL}$, respectively, with an average of $7.420 \mathrm{ng} \mathrm{h} / \mathrm{mL}$. The $\mathrm{AUC}_{0-\infty}$ values for subjects 1,2 , and 3 
Table 1: Pharmacokinetics profile of three healthy subjects

\begin{tabular}{|c|c|c|c|c|c|c|}
\hline Number of subject & $\mathrm{C}_{\max }(\mathrm{ng} / \mathrm{mL})$ & $\mathbf{t}_{\max }(\mathbf{h})$ & t $1 / 2$ (h) & $\mathrm{AUC}_{0-\mathrm{t}}(\mathrm{ng} \mathrm{h} / \mathrm{mL})$ & $\mathrm{AUC}_{0-\infty}(\mathrm{ng} \mathrm{h} / \mathrm{mL})$ & $\mathrm{AUC}_{0-\mathrm{t}} / \mathrm{AUC}_{0-\infty}(\%)$ \\
\hline 1 & 1.074 & 1 & 5.49 & 7.870 & 8.420 & 93.47 \\
\hline 2 & 1.114 & 1.25 & 7.63 & 6.692 & 7.333 & 91.26 \\
\hline Average & 1.146 & 1.083 & 7.013 & 7.420 & 8.110 & 91.49 \\
\hline SD & 0.09 & 0.14 & 1.33 & 0.64 & 0.68 & 1.87 \\
\hline$\% \mathrm{CV}$ & 8.05 & 13.32 & 18.92 & 8.58 & 8.36 & 2.04 \\
\hline
\end{tabular}

SD: Standard deviation, \% CV: Coefficient of variation percentage, $\mathrm{C}_{\max }$ : Maximum concentrations, $\mathrm{t}_{\max }$ : Maximum concentrations, AUC: Area under curve

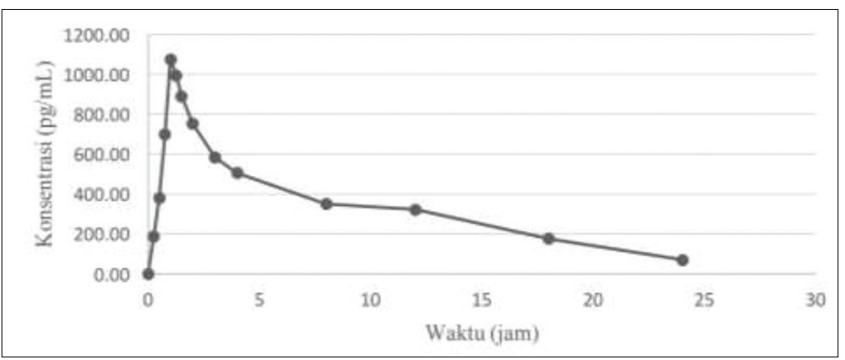

Fig 1: Plasma Concentration Versus Time Curve of Subject 1 After Administration of $75 \mathrm{mg}$ Clopidogrel Tablet

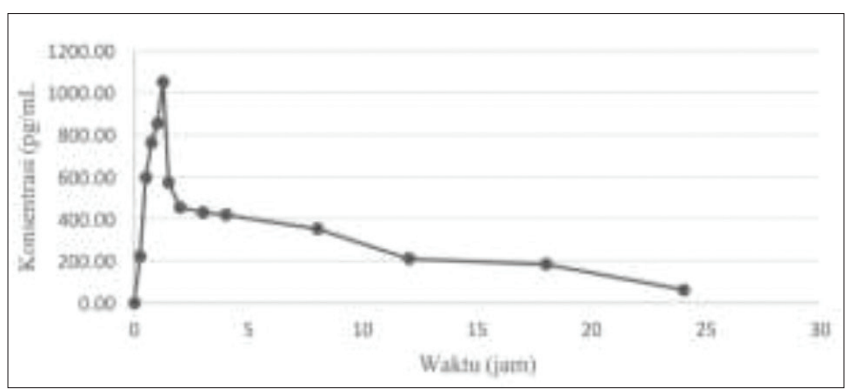

Fig 2: Plasma Concentration Versus Time Curve of Subject 2 After Administration of $75 \mathrm{mg}$ Clopidogrel Tablet

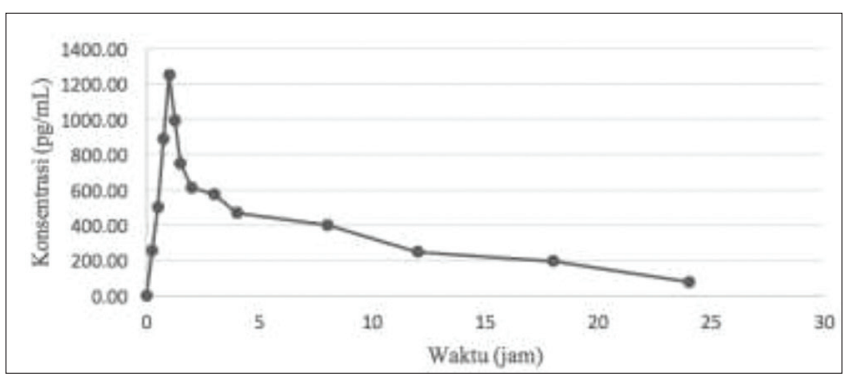

Fig 3: Plasma Concentration Versus Time Curve of Subject 3 After Administration of $75 \mathrm{mg}$ Clopidogrel Tablet

were $8.84,7.36$, and $8.58 \mathrm{ng} \mathrm{h} / \mathrm{mL}$, respectively, with an average of $8.111 \mathrm{ng} \mathrm{h} / \mathrm{mL}$. The $\mathrm{t}^{1} / 2$ values for subjects 1,2 , and 3 were $5.49,7.63$, and $7.92 \mathrm{~h}$, respectively, with an average of $7.01 \mathrm{~h}$.

The $t_{\text {max }}$ obtained in this study did not differ greatly from that reported in previous work, which was about $1 \mathrm{~h}$. However, the $\mathrm{C}_{\text {max }}$ value obtained was substantially lower - almost half - of that reported by KaraźniewiczŁada et al. [8].

The $\mathrm{AUC}_{0-\mathrm{t}}$ and $\mathrm{AUC}_{0-\infty}$ values were larger than those reported in the previous three studies, and the difference is considerable when compared with findings from Reddy et al. The AUC value is useful as a measurement of the total number of active drugs that reach the systemic circulation. The $\mathrm{AUC}_{0-\mathrm{t}}$ value was obtained from the AUC value at a zero- time concentration to the AUC value at the last measured concentration or $24 \mathrm{~h}$, whereas the $\mathrm{AUC}_{0-\infty}$ value is the value of AUC obtained at the concentration of time 0 to infinite time. According to the bioequivalence test manual of Brachial Plexus Outcome Measure, the $\mathrm{AUC}_{0-\mathrm{t}}$ value obtained should be $>80 \%$ of the $\mathrm{AUC}_{0-\infty}$. The average $\mathrm{AUC}_{0-\mathrm{t}}$ value in this study met the criteria of $7.420 \mathrm{ng} \mathrm{h} / \mathrm{mL}$ since it was $>80 \%$ of the average $\mathrm{AUC}_{0-\infty}$, that is, $8.110 \mathrm{ng} \mathrm{h} / \mathrm{mL}$, indicating that determination of the sampling time was optimal. In pharmacokinetics studies, AUC is the most relevant parameter for bioavailability assessment because it describes the total amount of drug absorbed and present in systemic circulation.

The $t^{1} / 2$ value, which is the time taken for half the concentration of drug to be eliminated, obtained in this study was also greater than that reported in previous studies of $7.013 \mathrm{~h}$ but not much different than that reported by Zou et al. of $6.9 \mathrm{~h}$. The half-life can be affected by metabolic processes and excretion [10].

Differences in these values compared with previous studies may be due to differences in tablet formulation. Differences in outcomes may also be due to subject differences, such as differences in metabolic rates and excretions between racial groups. In this study, different pharmacokinetics profiles were obtained between subjects, although the differences were not statistically significant, suggesting differences in the activities carried out by the subject during the sampling process.

\section{CONCLUSION}

Clopidogrel analysis using a UPLC-MS/MS with liquid-liquid extraction method was carried out using plasma samples from three healthy subjects who administered $75 \mathrm{mg}$ of clopidogrel tablet. The linear calibration curve obtained was in the range of $20-5000 \mathrm{pg} / \mathrm{mL}$. The obtained pharmacokinetics profile had average values as follows: $\mathrm{C}_{\max }=1.146 \mathrm{ng} / \mathrm{mL}, \mathrm{t}_{\max }=1 \mathrm{~h}, \mathrm{t} 1 / 2=7.01 \mathrm{~h}, \mathrm{AUC}_{0-\mathrm{t}}=7.420 \mathrm{ng} \mathrm{h} / \mathrm{mL}$, and $\mathrm{AUC}_{0-\infty}=8.111 \mathrm{ng} \mathrm{h} / \mathrm{mL}$.

\section{CONFLICTS OF INTEREST}

All authors have none to declare.

\section{REFERENCES}

1. European Medicines Agency. Assessment Report for Clopidogrel Teva. London: European Medicines Agency; 2009.

2. Indonesia National Agency of Food and Drug Control. Regulation from Head of Indonesia National Agency of Food and Drug Control No. HK.03.1.23.12.11.10217 about Drugs Obligate Equivalence Test. Jakarta; 2011. [In Indonesian]

3. Alesci J, Victorino A. Clopidogrel. New York: Nova Biomedical/Nova Science; 2014.

4. Bhargav K, Venkata SB, Venkata SK, Himaja G, Samuel GG, Bhaskar RK. Pharmacokinetic drug interaction between clopidogrel and esomeprazole in adult healthy male volunteers. Asian J Pharm Clin Res 2017;10:336-41.

5. Gurupadayya BM, Sama S. Bio-analytical determination of clopidogrel and pantoprazole by RP-HPLC method in rat plasma: Application to drug interaction study. Asian J Pharm Clin Res 2014;7:10-3.

6. Reddy DN. Design, development and characterization of clopidogrel bisulfate transdermal drug delivery system. Asian J Pharm Clin Res 2015;8:277-80. 
7. Harahap Y. Role of Bioanalysis in Assuring Drug Quality and Increasing Quality of Patient Life. Depok: UI Press; 2010.

8. Karaźniewicz-Łada M, Danielak D, Teżyk A, Żaba C, Tuffal G, Główka F. HPLC-MS/MS method for the simultaneous determination of clopidogrel, its carboxylic acid metabolite and derivatized isomers of thiol metabolite in clinical samples. J Chromatogr B 2012;911:105-12.

9. Divi KR, Jayaveera KN, Naidu YK, Reddy MK. Development and validation of high-throughput liquid chromatography-tandem mass spectrometric method for simultaneous quantification of clopidogrel and its metabolite in human plasma. J Chromatogr B 2010;878:502-8.

10. Zou JJ, Tan J, Fan HW, Chen SL. Bioequivalence study of clopidogrel $75 \mathrm{mg}$ tablets in healthy male volunteers. J Bioequiv Bioavailab 2012;4:6-9.

11. European Medicines Agency. Guideline on Bioanalytical Method Validation. London: European Medicines Agency; 2011

12. Robinson A, Hillis J, Neal C, Leary AC. The validation of a bioanalytical method for the determination of clopidogrel in human plasma. J Chromatogr B 2007;848:344-54. 